\title{
Ethnopharmacological use of potassium permanganate in South African traditional medicine
}

\author{
R A Street, ${ }^{1} \mathrm{PhD} ; \mathrm{G}$ M Kabera,${ }^{2} \mathrm{PhD} ; \mathbf{C}$ Connolly, ${ }^{3} \mathrm{MPH}$ \\ ${ }^{1}$ Environment and Health Research Unit, South African Medical Research Council, Durban; and Discipline of Occupational and \\ Environmental Health, School of Nursing and Public Health, University of KwaZulu-Natal, Durban, South Africa \\ ${ }^{2}$ Department of Statistics, University of South Africa, Florida Campus, South Africa \\ ${ }^{3}$ Biostatistics Unit, South African Medical Research Council, Durban, South Africa
}

Corresponding author: R A Street (renee.street@mrc.ac.za)

Background. Potassium permanganate $\left(\mathrm{KMnO}_{4}\right)$, which is widely available, is often used by traditional health practitioners (THPs) in South Africa (SA) without taking its potentially harmful properties into account. The crystalline $\mathrm{KMnO}_{4}$ salt is sold at traditional medicine markets and shops throughout SA. However, to date, traditional uses of $\mathrm{KMnO}_{4}$ remain undocumented.

Objective. To describe $\mathrm{KMnO}_{4}$ use by THPs in KwaZulu-Natal, SA.

Methods. This sub-study is part of a larger study investigating substances used in SA traditional medicine that are collectively known as imikhando in isiZulu - literally translated as 'ore. THPs $(N=201)$ were interviewed in the local language (isiZulu) by trained interviewers. Information on the reasons for using/not using $\mathrm{KMnO}_{4}$, the source of information on its use and modes of administration were collected. Results. $\mathrm{KMnO}_{4}$ was used as a constituent of traditional medicine by $158(79 \%)$ THPs. Their knowledge of $\mathrm{KMnO}_{4}$ use was acquired predominantly from fellow THPs $(n=134 ; 85 \%)$. Reasons for use included skin rash or wounds $(n=99,63 \%)$ and to treat aches, pains and swelling $(n=74 ; 47 \%)$. The main modes of administration were in the bath $(n=94 ; 60 \%)$, orally $(n=67 ; 42 \%)$ and in herbal compresses $(n=66$; $42 \%)$. The principal reason of the 43 THPs for not administering $\mathrm{KMnO}_{4}$ was not knowing how to use it $(n=29 ; 71 \%)$.

Conclusions. This study has identified traditional medicine users at risk of manganese toxicity owing to commonly used sociocultural practices. In particular, reports of oral ingestion and use in enemas are cause for concern. This public health issue needs regulatory measures and education programmes to enlighten the population against possible harm caused by $\mathrm{KMnO}_{4}$ exposure.

S Afr Med J 2018;108(3):187-189. DOI:10.7196/SAMJ.2018.v108i3.12606

Potassium permanganate $\left(\mathrm{KMnO}_{4}\right)$ is an industrially significant manganese $(\mathrm{Mn})$ compound of economic importance. ${ }^{[1]}$ At room temperature, it exists as a fragrance-free, dark purple crystalline substance with a metallic sheen. It is readily water soluble, and aqueous solutions are pink to violet in colour, depending on the strength. ${ }^{[2]} \mathrm{KMnO}_{4}$ is a powerful oxidising agent and is commonly used medicinally as a topical antiseptic agent. ${ }^{[3,4]}$ Nonetheless, overthe-counter availability of $\mathrm{KMnO}_{4}$ may contribute to its potentially harmful properties being overlooked. For example, ingestion of $\mathrm{KMnO}_{4}$ may result in widespread systemic toxicity that can cause major morbidity and even mortality. ${ }^{[5]}$

In South Africa (SA), $\mathrm{KMnO}_{4}$ poisoning in both adults and children has been reported for decades. ${ }^{[6-9]} \mathrm{A}$ recent study revealed 46 childhood poisonings by $\mathrm{KMnO}_{4}$ at a single hospital over a 5-year period (2003 - 2008), eight of which included severe corrosive injuries. ${ }^{[8]} \mathrm{Mn}$, in the form of $\mathrm{KMnO}_{4}$, is one of the main metals implicated in traditional medicine poisonings in SA. ${ }^{[10]}$ The crystalline $\mathrm{KMnO}_{4}$ salt is easily obtainable at traditional medicine markets and shops throughout SA. ${ }^{[1]}$ However, to date, traditional uses of $\mathrm{KMnO}_{4}$ have not been described; therefore, possible risks due to $\mathrm{KMnO}_{4}$-associated sociocultural practices remain unknown. The aim of this study was to document ethnopharmacological uses of $\mathrm{KMnO}_{4}$ in SA traditional medicine.

\section{Methods}

This sub-study on $\mathrm{KMnO}_{4}$ is part of a cross-sectional, descriptive study investigating metal and mineral substances used in SA traditional medicine, which are collectively known as imikhando in
isiZulu; this is literally translated as 'ore'. The results of our study on $\mathrm{KMnO}_{4}$, locally known as 'double buys' or umanyazini, are reported in this article. The sampling method was detailed previously. ${ }^{[12]}$ In brief, traditional health practitioners (THPs) were recruited from KwaZulu-Natal, SA. A total of 201 THPs were interviewed by trained interviewers and a structured questionnaire was administered in the local language, isiZulu. Data collected via the questionnaire were captured on an Excel spreadsheet, then exported to Stata version 14 (StataCorp., USA) for analysis. For certain questions related to $\mathrm{KMnO}_{4}$ use, multiple responses were allowed. Reasons for administering $\mathrm{KMnO}_{4}$, as well as routes of administration, were only included if they were independently reported by $\geq 5$ THPs. The participants signed an informed consent form prior to the start of the interview. The study was approved by the Biomedical Research Ethics Committee (BREC) of the University of KwaZulu-Natal (ref. no. BREC BF185/010).

\section{Results}

Of the 201 THPs interviewed, most were female $(n=142 ; 71 \%)$, $62 \%$ had practice experience of $>5$ years, and 30/190 (16\%) had no (formal) schooling (Table 1). About three-quarters of the respondents $(n=158 ; 79 \%)$ reported using $\mathrm{KMnO}_{4}$ as a constituent of SA traditional medicine. Gender, education and years of practice were not significantly associated with $\mathrm{KMnO}_{4}$ use (Table 1).

The THPs who used $\mathrm{KMnO}_{4}$ acquired the knowledge for usage from three different sources, i.e. fellow THPs, being self-taught or their ancestors ( $n=134,85 \% ; n=12,8 \%$; and $n=11,7 \%$, respectively) (results not tabulated, 1 missing response). 
Table 1. Demographic characteristics of study participants, stratified by $\mathrm{KMnO}_{4}$ use

\begin{tabular}{|c|c|c|c|c|}
\hline Characteristics & Total $(N=201)$ & $\mathrm{KMnO}_{4}$ users $(n=158)$ & Non- $\mathrm{KMnO}_{4}$ users $(n=43)$ & $p$-value \\
\hline Gender, $n(\%)$ & & & & 0.073 \\
\hline Female & $142(70.6)$ & $116(73.4)$ & $26(60.5)$ & \\
\hline Male & $59(29.4)$ & $42(26.6)$ & $17(39.5)$ & \\
\hline \multicolumn{2}{|c|}{ Years of practice (in 5-year intervals), $n(\%)^{*}$} & & & 0.166 \\
\hline$\leq 5$ & $75(38.1)$ & $57(36.8)$ & $18(41.9)$ & \\
\hline $5.1-10$ & $40(20.3)$ & $31(20.7)$ & $9(20.9)$ & \\
\hline $10.1-20$ & $47(23.9)$ & $34(21.9)$ & $13(30.2)$ & \\
\hline$>20$ & $35(17.8)$ & $32(20.7)$ & $3(7.0)$ & \\
\hline \multicolumn{2}{|l|}{ Education, $n(\%)^{\dagger}$} & & & 0.926 \\
\hline None & $30(15.8)$ & $25(17.0)$ & $5(11.9)$ & \\
\hline Lower primary & $41(21.6)$ & $32(21.6)$ & $9(21.4)$ & \\
\hline Higher primary & $29(15.3)$ & $23(15.5)$ & $6(14.3)$ & \\
\hline Attended high school & $69(36.3)$ & $53(35.8)$ & $16(38.1)$ & \\
\hline Completed high school & $16(8.4)$ & $11(7.4)$ & $5(11.9)$ & \\
\hline Tertiary & $5(2.6)$ & $4(2.7)$ & $1(2.4)$ & \\
\hline
\end{tabular}

The 43 THPs provided six reasons for not administering $\mathrm{KMnO}_{4}$, including: (i) not knowing how to use it ( $n=29 ; 71 \%$ ); (ii) it being unsafe ( $n=6 ; 15 \%)$; (iii) not believing in it $(n=3 ; 7 \%)$; (iv) according to their ancestors they should not use it $(n=1 ; 2 \%) ;(v)$ only using African medicine $(n=1 ; 2 \%)$; and $(v i)$ only using traditional medicine dug from the ground, e.g. plants $(n=1 ; 2 \%)$ (Table 2).

Table 3 presents, in descending frequency, the 11 principal reasons provided by the 158 THPs for administering $\mathrm{KMnO}_{4}$. The main responses included use for skin rash or wounds ( $n=99 ; 63 \%)$, aches, pains and swelling $(n=74 ; 47 \%)$ and gastrointestinal disorders $(n=33 ; 21 \%)$.

Eight modes of $\mathrm{KMnO}_{4}$ administration were reported, with the main methods being use in the bath $(n=94 ; 60 \%)$, orally $(n=67 ; 42 \%)$ and herbal compresses $(n=66 ; 42 \%)$ (Table 4$)$. Administration of $\mathrm{KMnO}_{4}$ by means of an enema was reported by $44(28 \%)$ of THPs.

\section{Discussion}

Our study revealed a larger proportion of female than male THPs using $\mathrm{KMnO}_{4}$ in their healing practice ( $82 \%$ and $71 \%$, respectively). The majority of the THPs using $\mathrm{KMnO}_{4}$ acquired the knowledge for usage from fellow THPs; however, with the diverse modes of administration and reasons for use, it was evident that the information relayed was not standardised and in certain cases may be harmful to traditional medicine users.

$\mathrm{Mn}$ is recognised as an essential micronutrient, but the acute toxicity of $\mathrm{KMnO}_{4}$ is defined by its oxidant/irritant properties and by the toxicity of $\mathrm{Mn} .{ }^{[13]}$ The symptoms of $\mathrm{KMnO}_{4}$ poisoning depend on the route of exposure, which is most commonly ingestion. ${ }^{[14]}$ The findings of our study revealed that $42 \%$ of the THPs administer $\mathrm{KMnO}_{4}$ orally. Manifestations of oral intake include nausea and vomiting in mild cases ${ }^{[15,16]}$ Owing to its caustic action, burns and ulceration of the mouth, oesophagus and stomach may occur. ${ }^{[5,16]}$ Another common mode of $\mathrm{KMnO}_{4}$ administration is by means of an enema, as reported by $28 \%$ of the THPs. Caustic enemas may have devastating consequences. ${ }^{[9,17]}$ Enemas containing caustic substances may be more damaging than ingestion because of the increased tissue contact time in the lower gastrointestinal tract. ${ }^{[17]}$ Nonetheless, little is known about treatment and prognosis. ${ }^{[17]}$

Two-thirds of the THPs in our study administered $\mathrm{KMnO}_{4}$ for healing of wounds and/or skin conditions. This is consistent with the
Table 2. Traditional health practitioners' reasons for not administering $\mathrm{KMnO}_{4}$

\begin{tabular}{ll}
\hline Reason $\left(\boldsymbol{N}=\mathbf{4 1} \mathbf{1}^{*}\right)$ & $\boldsymbol{n}(\%)$ \\
\hline Don't know how to use it & $29(70.7)$ \\
It is not safe to use & $6(14.6)$ \\
Don't believe in it & $3(7.3)$ \\
Ancestors say you must not use it & $1(2.4)$ \\
Only use African traditional medicine & $1(2.4)$ \\
Only use plants & $1(2.4)$ \\
${ }^{*}$ Two responses missing. &
\end{tabular}

Table 3. Health conditions identified for treatment with $\mathrm{KMnO}_{4}^{*}$

\begin{tabular}{ll}
\hline Reason $(\boldsymbol{N = 1 5 8 )}$ & $\boldsymbol{n}(\%)^{\dagger}$ \\
\hline Skin rash or wounds & $99(62.7)$ \\
Aches, pains and swelling & $74(46.8)$ \\
Gastrointestinal: aches and cramps & $33(20.9)$ \\
Sexually transmitted diseases & $23(14.6)$ \\
Nervous conditions & $23(14.6)$ \\
Blood cleaning & $14(8.9)$ \\
Kidney and/or bladder & $13(8.2)$ \\
Aphrodisiac & $7(4.4)$ \\
Impotence & $6(3.8)$ \\
Gynaecological & $5(3.2)$ \\
HIV & $5(3.2)$ \\
${ }^{*}$ Multiple responses allowed. \\
'Reported by $\geq 5$ traditional health practitioners.
\end{tabular}

customary use of $\mathrm{KMnO}_{4}$, i.e. the disinfecting and cleaning of wounds and as a general topical skin antiseptic. ${ }^{[18]}$ Nonetheless, despite its long history of use, there is a lack of evidence to support $\mathrm{KMnO}_{4}$ to aid the management of exuding wounds; therefore, its medicinal indication remains controversial. ${ }^{[19,20]}$ It is interesting to note that the study by Balme et al ${ }^{[8]}$ on childhood poisoning in SA classified toxic substances according to the intended use of the agent and classified $\mathrm{KMnO}_{4}$ as an antiseptic agent. Our study provides evidence to consider the classification of $\mathrm{KMnO}_{4}$ under the agent category of traditional medicine. 
Table 4. Traditional health practitioners' various administration modes for $\mathrm{KMnO}_{4} \mathrm{use}^{*}$

\begin{tabular}{ll}
\hline Administration mode $(\boldsymbol{N = 1 5 8 )}$ & $\boldsymbol{n}(\%)^{\dagger}$ \\
\hline In bath & $94(59.9)$ \\
Oral & $67(42.4)$ \\
Herbal compress & $66(41.8)$ \\
Enema & $44(27.9)$ \\
Cutaneous implantations & $25(15.8)$ \\
Licking off finger tips & $8(5.1)$ \\
Inhalation/facial sauna & $7(4.4)$ \\
Licking off hand & $6(3.8)$ \\
${ }^{*}$ Multiple responses allowed. & \\
${ }^{+}$Reported by $\geq 5$ traditional health practitioners. &
\end{tabular}

Our study revealed the use of $\mathrm{KMnO}_{4}$ for a range of sexual issues, including sexually transmitted infections (STIs) (23\%), as an aphrodisiac (4\%), and for impotence (4\%). The oral use of $\mathrm{KMnO}_{4}$ as an alternative treatment to prevent or cure STIs has previously been reported in SA. ${ }^{[21,22]}$ Our study further revealed the use of $\mathrm{KMnO}_{4}$ for HIV infection; however, the exact specification (e.g. prevention, management) is not given. In China, $\mathrm{KMnO}_{4}$ is reportedly used by female sex workers to prevent HIV and STIs, ${ }^{[23]}$ despite there being no supporting scientific evidence. ${ }^{[23]}$

Although general symptoms of $\mathrm{Mn}$ toxicity include nausea, vomiting and gastrointestinal tract disturbances, ${ }^{[5,18]}$ there is a need for a comprehensive understanding of Mn risk, the mechanism of toxicity, clinical interventions, as well as primary prevention strategies. ${ }^{[24]}$

\section{Conclusion}

There is a growing body of evidence relating to Mn toxicities from a range of sources, which signifies its public health importance. ${ }^{[24]}$ This study has identified traditional medicine users at risk of poisoning owing to sociocultural practices involving $\mathrm{KMnO}_{4}$. Healthcare providers may be unaware of the metal salts used in traditional medicine; therefore, circumstances around $\mathrm{KMnO}_{4}$ poisonings may be inaccurately documented and/or under-reported. To this end, the lack of an SA medicine pharmacopoeia is a public health threat. Furthermore, there is a need for poisoning prevention programmes that are locally relevant and culturally cognisant.

Acknowledgements. The authors would like to thank their respective institutions for financial support.

Author contributions. RAS initiated the concept and oversaw the study data collection. GMK and CC performed the statistical analyses and interpreted the results. RAS, GMK and CC drafted the manuscript, and read and approved the final manuscript. The content of this publication is solely the responsibility of the authors and does not necessarily represent the official views of any of the institutions mentioned above.

Funding. This project was funded by the South African Medical Research Council (SAMRC), funding provided to the principal investigator from the SAMRC's Career Development Awards Programme. The University of KwaZulu-Natal, Durban, is thanked for additional funding.

Conflicts of interest. None.

1. Büchel KH, Moretto H-H, Werner D. Industrial Inorganic Chemistry. 2nd ed.Wiley-VCH: Weinheim, Germany, 2008:289-291.

2. Cevik SE, Yesil O, Ozturk TC, Guneysel O. Potassium permanganate ingestion as a suicide attempt. Clin Pract 2012;2(e32):77-78. https://doi.org/10.4081/cp.2012.e32

3. Middleton S, Jacyna M, McClaren D, Robinson R, Thomas H. Haemorrhagic pancreatitis - a cause of Middleton S, Jacyna M, McClaren D, Robinson R, Thomas H. Haemorrhagic pancreatitis - a cause of
death in severe potassium permanganate poisoning. Postgrad Med J 1990;66(778):657-658. https://doi. org/10.1136/pgmj.66.778.657

4. Agrawal VK, Bansal A, Kumar R, Kumawat BL, Mahajan P. Potassium permanganate toxicity: A rare case with difficult airway management and hepatic damage. Ind J Crit Care Med 2014;18(12):819-821. https://doi.org/10.4103/0972-5229.146318

5. Ong KL, Tan T, Cheung W. Potassium permanganate poisoning - a rare cause of fatal self poisoning J Accident Emerg Med 1997;14(1):43-45. https://doi.org/10.1136/emj.14.1.43

6. Lewis H, Cronje R, Naude S, van den Berg C. Accidental poisoning in childhood. S Afr Med J 1989;769(8):429-431.

7. Malangu N, Ogunbanjo G. A profile of acute poisoning at selected hospitals in South Africa. South Afr J Epidemiol Infect 2009;24(2):14-16. https://doi.org/10.1080/10158782.2009.11441343

8. Balme K, Roberts JC, Glasstone M, Curling L, Mann MD. The changing trends of childhood poisoning at a tertiarychildren's hospital in South Africa. S Afr Med J 2012;102(3):142-146.

9. Segal I, Tim LO, Hamilton DG, et al. Ritual-enema-induced colitis. Dis Colon Rectum 1979;22(3):195199. https://doi.org/10.1007/BF02586822
19.

10. Steenkamp V, Stewart MJ, Curowska E, Zuckerman M. A severe case of multiple metal poisoning in a Steenkamp V, Stewart MJ, Curowska E, Zuckerman M. A severe case of multip.
child treated with a traditional medicine. Forens Sci Int 2002;128(3):123-126.

11. Street R, Cele M. Commonly used metal and crystalline salts in South African traditional medicine. J Ethnopharmacol 2013;148(1):329-331. https://doi.org/10.1016/j.j.jp.2013.03.054

12. Street RA, Kabera GM, Connolly C. Metallic mercury use by South African traditional health practitioners: Perceptions and practices. Environm Health 2015;14(67):1-7. https://doi.org/10.1186 s12940-015-0053-4

13. Willhite C, Bhat V, Ball G, McLellan C. Emergency do not consume/do not use concentrations for potassium permanganate in drinking water. Hum Experiment Toxicol 2013;32(3):275-298. https://doi org/10.1177/0960327112456316

14. Eteiwi SM, Al-Eyadah AA, Al-Sarihin KK, Al-Omari AA, Al-Asaad RA, Haddad FH. Potassium permanganate poisoning: A nonfatal outcome. Oman Med J 2015;30(4):291-294. https://doi.org/10.5001/ omj.2015.57

15. Karthik R, Veerendranath HPK, Wali S, Mohan MN, Kumar PA, Trimurty G. Suicidal ingestion of potassium permanganate crystals: A rare encounter. Toxicol Int 2014;21(3):331-334. https://doi. potassium permanganate crys
org $/ 10.4103 / 0971-6580.155392$

16. Korkut E, Saritas A, Aydin Y, Korkut S, Kandis H, Baltaci D. Suicidal ingestion of potassium Korkut E, Saritas A, Aydin Y, Korkut S, Kandis H, Baltaci D. Suicidal ingestion of potassium
permanganate. World J Emerg Med 2013;4(1):73-74. https://doi.org/10.5847/wjem.j.issn.1920-8642. permanganate. World J Emerg Med 2013;4(1):73-74. https://doi.org/10.5847/wjem.j.issn.1920-8642.
2013.01.014 17. Salzman M, O’Malley RN. Updates on the evaluation and management of cau
Med Clin N Am 2007;25(2):459-476. https://doi.org/10.1016/..emc.2007.02.007

18. Saganuwan S, Ahur V, Yohanna C. Acute toxicity studies of potassium permanganate in Swiss albino mice. Niger J Physiol Sci 2008;23(1-2):31-35.

9. Anderson I. Should potassium permanganate be used in wound care? Nurs Times 2003;99(31):61.

20. Kujath P, Michelsen A. Wounds - from physiology to wound dressing. Deutsch Arzteblatt Int 2008;105(13):239-248. https://doi.org/10.3238/arztebl.2008.0239

21. Shefer $T$, Strebel A, Wilson $T$, et al. The social construction of sexually transmitted infections (STIs) in South African communities. Qual Health Res 2002:12(10):1373-1390. https.//doi. org/10.1177/1049732302238749

22. Macheke C, Campbell C. Perceptions of HIV/AIDS on a Johannesburg gold mine. S Afr J Psychol 1998;28(3):146-153. https://doi.org/10.1177/008124639802800304

23. Jie W, Xiaolan Z, Ciyong L, et al. A qualitative exploration of barriers to condom use among female sex workers in China. PLOS ONE 2012;7(10):1-7. https://doi.org/10.1371/journal.pone.0046786

24. O'Neal SL, Zheng W. Manganese toxicity upon overexposure: A decade in review. Curr Environ Health Rep 2015;2(3):315-328. https://doi.org/10.1007/s40572-015-0056-x

Accepted 2 October 2017 